\title{
MRI Evidence of Altered Callosal Sodium in Mild Traumatic Brain Injury
}

\author{
(D). Grover, (D) Y. Qian, DF.E. Boada, (D). Lakshmanan, DS. Flanagan, and (D).W. Lui
} $\times \mathrm{O}=$

\begin{abstract}
BACKGROUND AND PURPOSE: Mild traumatic brain injury is a leading cause of death and disability worldwide with 42 million cases reported annually, increasing the need to understand the underlying pathophysiology because this could help guide the development of targeted therapy. White matter, particularly the corpus callosum, is susceptible to injury. Animal models suggest stretch-induced mechanoporation of the axonal membrane resulting in ionic shifts and altered sodium ion distribution. The purpose of this study was to compare the distribution of total sodium concentration in the corpus callosum between patients with mild traumatic brain injury and controls using sodium $\left({ }^{23} \mathrm{Na}\right) \mathrm{MR}$ imaging.
\end{abstract}

MATERIALS AND METHODS: Eleven patients with a history of mild traumatic brain injury and 10 age- and sex-matched controls underwent sodium ( ${ }^{23} \mathrm{Na}$ ) MR imaging using a $3 \mathrm{~T}$ scanner. Total sodium concentration was measured in the genu, body, and splenium of the corpus callosum with 5-mm ROls; total sodium concentration of the genu-to-splenium ratio was calculated and compared between patients and controls.

RESULTS: Higher total sodium concentration in the genu (49.28 versus $43.29 \mathrm{mmol} / \mathrm{L}, P=.01$ ) and lower total sodium concentration in the splenium (which was not statistically significant; 38.35 versus $44.06 \mathrm{mmol} / \mathrm{L}, P=.08$ ) was seen in patients with mild traumatic brain injury compared with controls. The ratio of genu total sodium concentration to splenium total sodium concentration was also higher in patients with mild traumatic brain injury (1.3 versus 1.01, $P=.001)$.

CONCLUSIONS: Complex differences are seen in callosal total sodium concentration in symptomatic patients with mild traumatic brain injury, supporting the notion of ionic dysfunction in the pathogenesis of mild traumatic brain injury. The total sodium concentration appears to be altered beyond the immediate postinjury phase, and further work is needed to understand the relationship to persistent symptoms and outcome.

ABBREVIATIONS: $\mathrm{CC}=$ corpus callosum; $\mathrm{mTBI}=$ mild traumatic brain injury; $\mathrm{TSC}=$ total sodium concentration

M ild traumatic brain injury (mTBI) is the leading cause of death and disability in the United States and worldwide, with approximately 42 million cases annually. ${ }^{1}$ Patients may have a complex array of symptoms, including cognitive disturbance, headache, and visual impairment, and there is a critical need to

Received July 30, 2017; accepted after revision September 27, 2018.

From the New York University Langone Medical Center, New York, New York.

This work was supported by R01 NS039135-11 and R21 NS090349, from the National Institute for Neurological Disorders and Stroke. It was also performed under the rubric of the Center for Advanced Imaging Innovation and Research $(C A)^{2} \mathrm{R}$ : www.cai2r.net), a National Institute of Biomedical Imaging and Bioengineering Biomedical Technology Resource Center (National Institutes of Health, P41 EB017183).

Please address correspondence to Yvonne W. Lui, MD, NYU Langone Medical Center, 660 1st Ave, NY, NY 10016; e-mail: Yvonne.Lui@nyumc.org; @cai2r

- Indicates open access to non-subscribers at www.ajnr.org

三 Indicates article with supplemental on-line table.

http://dx.doi.org/10.3174/ajnr.A5903 gain further insight into the pathophysiology underlying the injury. It is known that sodium is critical to cellular homeostasis, which maintains fluid volume in the intracellular and extracellular compartments, maintains resting potential across membranes, and triggers action potential. Mild TBI causes mechanical injury to axons, resulting in widespread membrane depolarizations and activation of cellular ionic cascades, thereby causing disruption of sodium homeostasis. ${ }^{2-4}$ There is a resultant increase in intracellular sodium, which lowers the threshold for membrane depolarization. ${ }^{4-8}$ White matter is known to be susceptible to injury in mTBI relating to acceleration, deceleration, and rotational forces. ${ }^{8,9}$ In particular, the corpus callosum (CC) is at specific risk due to axon density, transverse orientation, and connection of the 2 cerebral hemispheres, which can experience opposing forces during complex head injury. ${ }^{2}$ It is known from the biomechanical literature that quantitative stress measures such as principal strain, strain 
rate, ${ }^{10}$ and von Mises stress ${ }^{11}$ are highest in and around the CC. Because the CC is a group of anatomic tracts that integrate information across cerebral hemispheres, patients with mTBI tend to experience deficits in integrative functions (cognitive slowing, confusion, difficulty with complex tasks) rather than focal neurologic deficits.

Noninvasive imaging of brain sodium on clinical MR imaging scanners is very challenging due to low signal-to-noise ratio. Recent advances in technologies achieved at our site, such as coil design, data acquisition, and sodium quantification, now allow us to study ionic changes noninvasively at clinical field strengths of 3T or higher. ${ }^{12-16}$ The purpose of this pilot study was to measure total sodium concentration (TSC) in the CC in patients with mTBI using sodium $\left({ }^{23} \mathrm{Na}\right) \mathrm{MRI}$ and to compare TSC and its spatial distribution across the $\mathrm{CC}$ with that in healthy controls.

\section{MATERIALS AND METHODS}

The study was performed under approval by the institutional review board. Informed consent was obtained from each of the subjects studied.

\section{Human Subjects and Clinical Assessments}

Eleven patients (5 men and 6 women; age range, 19-70 years) with a history of mTBI (as defined by the American Congress of Rehabilitation Medicine ${ }^{9}$ ) and 10 age- and sex-matched healthy controls were prospectively recruited for sodium $\left({ }^{23} \mathrm{Na}\right) \mathrm{MRI}$. Review of clinical charts was performed for pertinent clinical history and assessment, including postconcussive symptoms, neurologic examination, and scores on the Standardized Assessment of Concussion.

\section{MR Imaging Acquisition}

Sodium $\left({ }^{23} \mathrm{Na}\right)$ MRI scans were performed on a clinical 3T scanner (Magnetom Prisma; Siemens, Erlangen, Germany) with a custom-built 8 -channel dual-tuned $\left({ }^{1} \mathrm{H}^{23} \mathrm{Na}\right)$ transmit/receive head array coil. ${ }^{13}$ The twisted projection imaging pulse sequence ${ }^{15,17}$ was applied to a $3 \mathrm{D}$ volume covering the whole head $(\mathrm{FOV}=220$ $\mathrm{mm}$, matrix size $=64,3 \mathrm{D}$ isotropic, nominal resolution $=3.44$ $\mathrm{mm}$, rectangular radiofrequency pulse duration $=0.5 \mathrm{~ms}$, TE/ $\mathrm{TR}=0.3 / 100 \mathrm{~ms}$, flip angle $=90^{\circ}$, rings $=28, P$ [key parameter $]=.4$, projections $=1595$, averages $=4$, TA [time of acquisition $]=10.6$ minutes). This scheme of data acquisition produced a typically high SNR of 55 in gray matter, 35 in white matter, and 57 in CSF in the square-root of the sum-of-squares sodium image of healthy controls before the correction for coil sensitivities. A magnetization-prepared rapid acquistion of gradient echo ${ }^{1} \mathrm{H}$-MR imaging pulse sequence was performed for structural imaging of the brain $\left(\mathrm{FOV}=256 \times 216 \mathrm{~mm}^{2}\right.$, matrix size $=384 \times$ 324 , slice thickness $=1 \mathrm{~mm}$ at 144 slices, $\mathrm{TE} / \mathrm{TR}=3.56 / 2,220 \mathrm{~ms}$, acceleration factor $=3$, TA $=4.6$ minutes).

\section{Image Preprocessing}

Sodium images were corrected for intensity inhomogeneity relating to the array coil by dividing by a low-resolution version of the images reconstructed from the $k$-space center of an optimally selected diameter of 9.0/FOV. ${ }^{18}$ Normalization was then accomplished with conversion of image intensity into sodium concen-

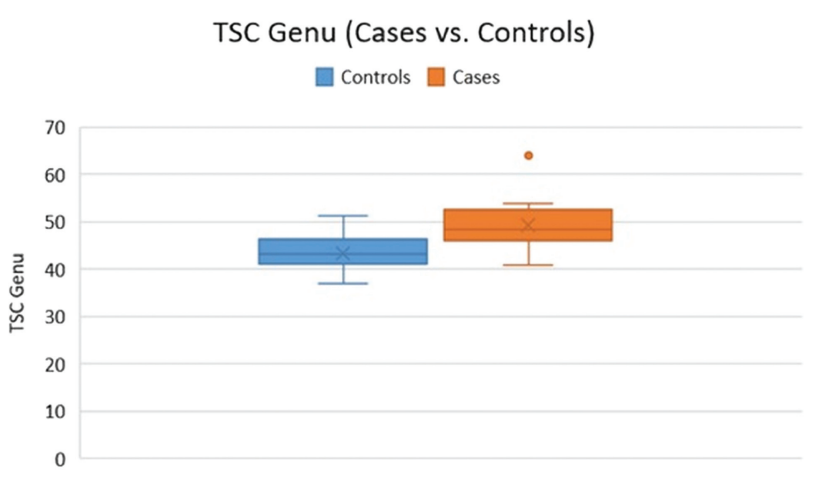

FIG 1. The TSC of the genu was higher in patients with mTBI compared with controls $(P=.01)$.

TSC Splenium (Cases vs. Controls)

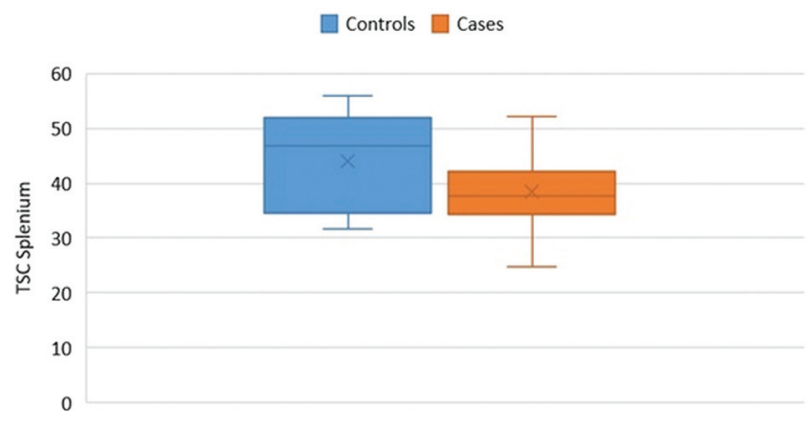

FIG 2. The TSC in the splenium was lower in patients with mTBI compared with controls $(P=.08)$.

tration in millimoles per liter on a pixel-by-pixel basis through a 2-point linear calibration ${ }^{16}$ with a noise-only background region set at $0 \mathrm{mmol} / \mathrm{L}$ and an ROI within the posterior chamber of the ocular globe set at a known (previously established) human vitreous sodium concentration of $145 \mathrm{mmol} / \mathrm{L}^{19,20}$

\section{ROI Analysis}

Circular ROIs of 5-mm in diameter were placed by 2 reviewers ( 1 research associate specifically working on neuroimaging and 1 neuroradiologist with $>10$ years of experience) in consensus in the genu, body, and splenium of the CC. A small-sized ROI was chosen to avoid volume averaging. The mean TSC was compared between subjects with mTBI and controls using a 2-tailed Student $t$ test and a significance level of .05 .

For further assessment of the TSC spatial distribution across the corpus callosum, a TSC ratio of genu to splenium was calculated and compared between patients and controls. A TSC color map was created using MR Viewer software (MRI Research Lab, Mayo Clinic and Foundation) (https://cortechsolutions.com/emse/ software/mr-viewer/).

\section{RESULTS}

Five men and six women with an age range 19-70 years and a history of mTBI were studied, with an average time since injury of 16 weeks. All patients were symptomatic at assessment. Ten of 11 subjects with mTBI had formal clinical assessments at our institution. One subject declined this assessment.

All of the 10 patients who underwent clinical assessment were symptomatic at time of imaging (detailed in the On-line Table). 
Of note, most patients reported headaches, sleep disturbances, dizziness, decreased concentration, and an average Standardized Assessment of Concussion score of 27.5 (highest Standardized Assessment of Concussion score $=30$, normal score $\geq 25$ ). ${ }^{21}$

The mean TSC in the genu, body, and splenium of the CC in patients with $\mathrm{mTBI}$ was $49.28 \pm 0.51 \mathrm{mmol} / \mathrm{L}, 46.04 \pm 0.43$ $\mathrm{mmol} / \mathrm{L}$, and $38.35 \pm 0.36 \mathrm{mmol} / \mathrm{L}$, respectively, compared with $43.29 \pm 0.46 \mathrm{mmol} / \mathrm{L}, 45.25 \pm 0.38 \mathrm{mmol} / \mathrm{L}$, and $44.06 \pm 0.46$ $\mathrm{mmol} / \mathrm{L}$ in controls. There were statistically significant differences between patients with $\mathrm{mTBI}$ and controls with respect to the callosal TSC in the genu (49.28 versus $43.29 \mathrm{mmol} / \mathrm{L}, P=.01$ )

TSC Genu/Spl Ratio (Cases vs. Controls)

$\square$ Controls $\square$ Cases

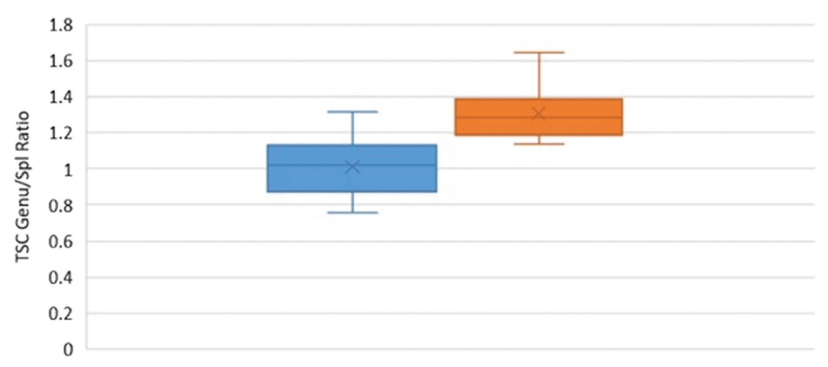

FIG 3. The TSC of the genu/splenium ratio was higher in patients compared with controls $(P=.001)$.
(Fig 1). No significant differences in the average TSC were found between patients and controls in the body $(P=.32)$ and splenium of the corpus callosum $(P=.08)$ (Fig 2).

The average ratio (genu/splenium) was 1.3 in patients and 1.01 in controls $(P=.001)$ (Fig 3).

\section{DISCUSSION}

The results of this investigation show differences in the callosal TSC between a small group of symptomatic patients with mTBI and age- and sex-matched healthy controls. Differences in the TSC between study groups varied depending on the location within the CC, with higher genu TSC and a trend that did not reach statistical significance of lower splenial TSC in patients with mTBI (Fig 4).

The findings corroborate a growing body of literature that underscores the importance of cytosolic sodium as a marker of tissue injury after trauma. In mTBI, twisting and stretching of axons results in mechanical disruption of membranes, altered function of voltage-gated sodium channels and sodium-potassium adenosine triphosphatase, $, 5,22$ and changed regulation of the expression of sodium channels, ${ }^{6,7}$ with potential persistent sodium abnormality.

It is not fully clear what caused the change of TSC in the CC: TSC has contributions from both intracellular and extracellular compartments, and derangements in either of these compart-
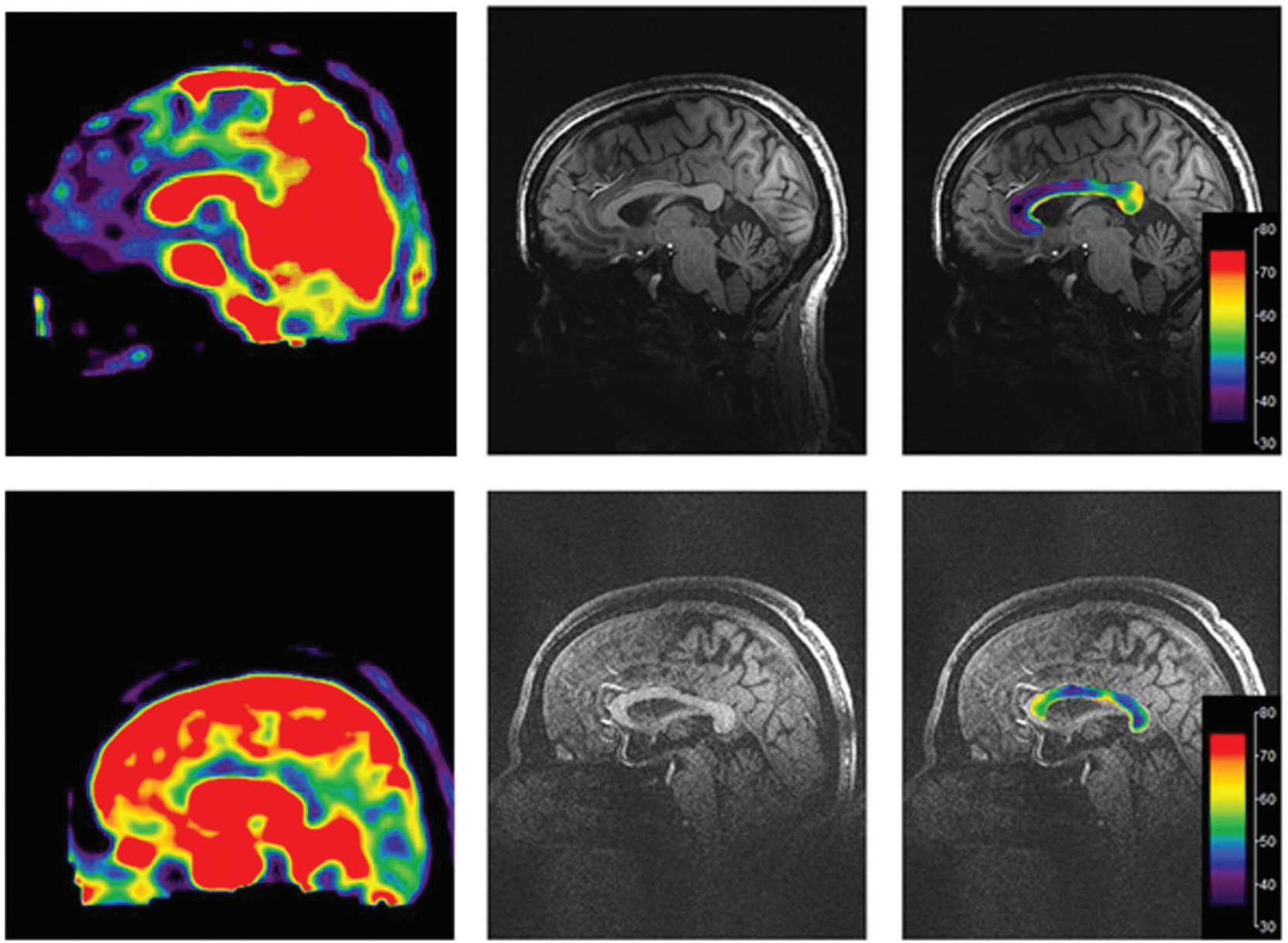

FIG 4. The TSC heat color map of the corpus callosum superimposed on a midline MPRAGE image in a control subject (top) and a patient with $\mathrm{mTBI}$ (bottom) shows that the TSC is higher in the genu and lower in the splenium in the patient with mTBI. 


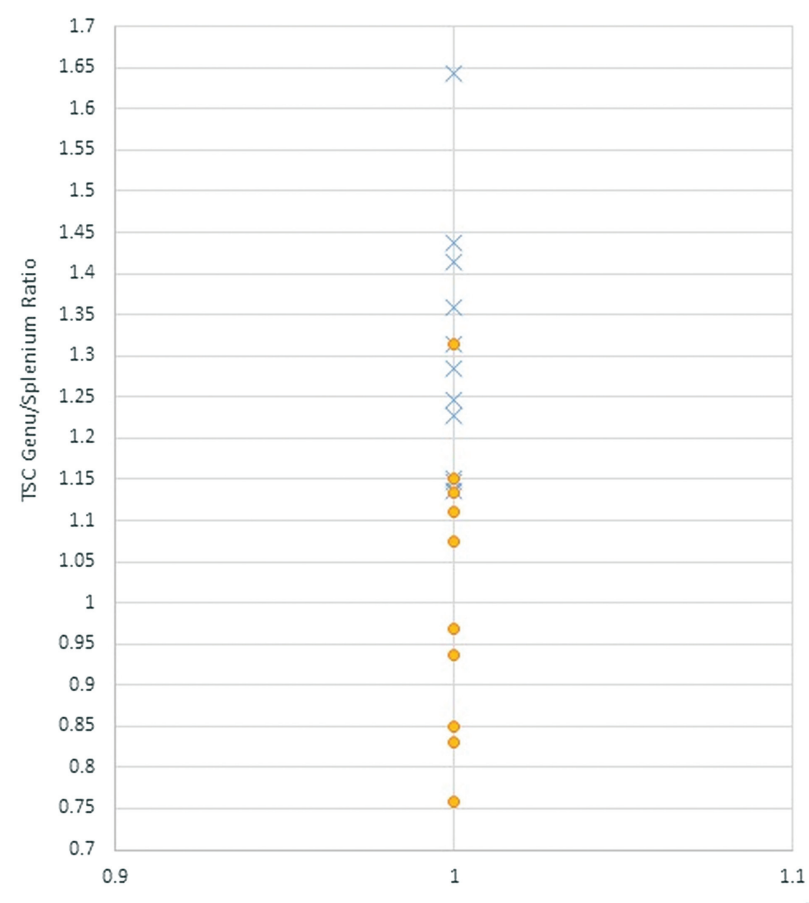

FIG 5. TSC genu/splenium ratio in patients with $\mathrm{mTBI}(X)$ and controls (O).

ments could contribute to the altered TSC. Because the extracellular compartment rapidly equilibrates with a larger plasma sodium pool, changes in intracellular sodium concentration could certainly affect TSC measures. ${ }^{23,24}$ Alterations in the relative size of the compartments would also be expected to affect TSC measurements. Work is currently underway to attempt to estimate intracellular and extracellular contributions to the TSC signal. ${ }^{16,23,25,26}$

Why injury may affect sodium differently across various parts of the CC is unclear. There is variable myelination across the CC, ${ }^{27-29}$ and expression of some specific voltage-gated sodium channels is known to track with myelination. ${ }^{30}$ In addition, von Reyn et $\mathrm{al}^{3}$ demonstrated anatomic redistribution of voltagegated sodium channels in the CC in an animal model of mTBI. These factors may contribute to anatomic differences in TSC across the CC after injury.

Many medications may affect sodium homeostasis. The most relevant ones were specifically screened and included in the chart review. Patient 5 was on the antidepressant escitalopram (selective serotonin reuptake inhibitor). There are a few recent reports of escitalopram causing a syndrome of inappropriate antidiuretic hormone secretion and hyponatremia. Our patient exhibited no signs of the syndrome of inappropriate antidiuretic hormone secretion and had normal serum chemistry values. Patient 3 was treated with lamotrigine, a central nervous system voltage-gated sodium channel blocker, for posttraumatic dystonia. In this subject, the TSC genu/splenium ratio among the mTBI group was the closest to that of the control cohort (Fig 5).

Limitations of this study include the small sample size; however, here we show proof of concept that TSC can be measured in vivo, noninvasively, on a clinical $3 \mathrm{~T}$ scanner in subjects with mTBI after injury. This represents the first report we are aware of suggesting sodium homeostasis abnormality in human subjects with mTBI using a noninvasive method. Already discussed is the need to estimate cellular compartmental contributions to the TSC to further elucidate ionic abnormalities in mTBI. This pilot work included a heterogeneous population of patients with respect to time since injury, history of prior mTBI, and medications that may affect the sodium balance. In this preliminary study, no T2WI/FLAIR was performed in these subjects.

\section{CONCLUSIONS}

This study shows complex differences in the TSC in the CC in symptomatic patients with mTBI compared with age- and sexmatched healthy controls. Specifically, the TSC in the genu of the CC was elevated. Further work is needed to understand the relationship between the TSC change and symptom resolution or outcome prediction.

Disclosures: Hemal Grover-RELATED: Grant: National Institutes of Health, Comments: R01NS039135-11.* Steven Flanagan—RELATED: Grant: National Institutes of Health, Comments: salary support for work on a grant*; UNRELATED: Grants/Grants Pending: National Institutes of Health, Comments: salary support as investigator on National Institutes of Health-funded research.* Yvonne W. Lui-RELATED: Grant: National Institutes of Health*; UNRELATED: Grants/Grants Pending: National Institutes of Health.* *Money paid to the institution.

\section{REFERENCES}

1. Gardner RC, Yaffe K. Epidemiology of mild traumatic brain injury and neurodegenerative disease. Mol Cell Neurosci 2015;66:75-80 CrossRef Medline

2. Prins M, Greco T, Alexander D, et al. The pathophysiology of traumatic brain injury at a glance. Dis Model Mech 2013;6:1307-15 CrossRef Medline

3. von Reyn CR, Mott RE, Siman R, et al. Mechanisms of calpain mediated proteolysis of voltage gated sodium channel $\alpha$-subunits following in vitro dynamic stretch injury. J Neurochem 2012;121:793805 CrossRef Medline

4. Wolf JA, Stys PK, Lusardi T, et al. Traumatic axonal injury induces calcium influx modulated by tetrodotoxin-sensitive sodium channels. J Neurosci 2001;21:1923-30 CrossRef Medline

5. Gardiner D. Quantitative Analysis of Contactin-Associated Protein and Voltage-Gated Sodium Channel Isoform 1.6 Following Experimental Diffuse Traumatic Brain Injury [Master of Science Thesis, Physiology]. Richmond: Virginia Commonwealth University; 2011

6. Mao Q, Jia F, Zhang XH, et al. The up-regulation of voltage-gated sodium channel Nav1.6 expression following fluid percussion traumatic brain injury in rats. Neurosurgery 2010;66:1134-39; discussion 1139 CrossRef Medline

7. Huang XJ, Mao Q, Lin Y, et al. Expression of voltage-gated sodium channel Nav1.3 is associated with severity of traumatic brain injury in adult rats. J Neurotrauma 2013;30:39-46 CrossRef Medline

8. Huang XJ, Li WP, Lin Y, et al. Blockage of the upregulation of voltage-gated sodium channel nav1.3 improves outcomes after experimental traumatic brain injury. J Neurotrauma 2014;1:346-57 CrossRef Medline

9. Ruff RM, Iverson GL, Barth JT, et al; NAN Policy and Planning Committee. Recommendations for diagnosing a mild traumatic brain injury: a National Academy of Neuropsychology education paper. Arch Clin Neuropsychol 2009;24:3-10 CrossRef Medline

10. McAllister TW, Ford JC, Ji S, et al. Maximum principal strain and strain rate associated with concussion diagnosis correlates with changes in corpus callosum white matter indices. Ann Biomed Eng 2012;40:127-40 CrossRef Medline

11. Patton DA, McIntosh AS, Kleiven S. The biomechanical determinants of concussion: finite element simulations to investigate tis- 
sue-level predictors of injury during sporting impacts to the unprotected head. J Appl Biomech 2015;31:264-68 CrossRef Medline

12. Wiggins GC, Brown R, Lakshmanan K. High-performance radiofrequency coils for (23) Na MRI: brain and musculoskeletal applications. NMR Biomed 2016;29:96-106 CrossRef Medline

13. Lakshmanan K, Brown R, Madelin G, et al. An eight-channel sodium/proton coil for brain MRI at 3 T. NMR Biomed 2018;31: e3867 CrossRef Medline

14. Qian Y, Zhao T, Wiggins GC, et al. Sodium imaging of human brain at 7 T with 15-channel array coil. Magn Reson Med 2012;68:1807-14 CrossRef Medline

15. Qian Y. Stenger VA. Boada FE. Parallel imaging with 3D TPI trajectory: SNR and acceleration benefits. Magn Reson Imaging 2009;27:656-63 CrossRef Medline

16. Qian Y, Panigrahy A, Laymon CM, et al. Short-T2 imaging for quantifying concentration of sodium ( $23 \mathrm{Na}$ ) of bi-exponential $\mathrm{T} 2$ relaxation. Magn Reson Med 2015;74:162-174 CrossRef Medline

17. Boada FE, Shen GX, Chang SY, et al. Spectrally weighted twisted projection imaging: reducing $\mathrm{T} 2$ signal attenuation effects in fast three-dimensional sodium imaging. Magn Reson Med 1997;38: 1022-28 CrossRef Medline

18. Qian Y, Zhang Z, Stenger VA, et al., Self-calibrated spiral SENSE. Magn Reson Med 2004;52:688-92 CrossRef Medline

19. Harrington MG, Salomon RM, Pogoda JM, et al. Cerebrospinal fluid sodium rhythms. Cerebrospinal Fluid Res 2010;7:3 CrossRef Medline

20. Kokavec J, Min SH, Tan MH, et al. Biochemical analysis of the living human vitreous. Clin Exp Ophthalmol 2016;44:597-609 CrossRef Medline

21. O’Neil B, Naunheim R, DeLorenzo R. CT positive brain injury in mild TBI patients presenting with normal SAC scores. Mil Med 2014;179:1250-53 CrossRef Medline

22. Paling D, Solanky BS, Riemer F, et al. Sodium accumulation is associated with disability and a progressive course in multiple sclerosis. Brain 2013;136:2305-17 CrossRef Medline

23. Madelin G, Kline R, Walvick R, et al. A method for estimating intracellular sodium concentration and extracellular volume fraction in brain in vivo using sodium magnetic resonance imaging. Sci Rep 2014;4:4763 CrossRef Medline

24. Alessandri B, Doppenberg E, Zauner A, et al. Cortical extracellular sodium transients after human head injury: an indicator of secondary brain damage? Acta Neurochir Suppl 1998;71:237-40 Medline

25. Fleysher L, Oesingmann N, Brown R, et al. Noninvasive quantification of intracellular sodium in human brain using ultrahigh-field MRI. NMR Biomed 2013;26:9-19 CrossRef Medline

26. Mirkes C, Shajan G, Bause J, et al. Triple-quantum-filtered sodium imaging at 9.4 Tesla. Magn Reson Med 2016;75:1278-89 CrossRef Medline

27. Knyazeva MG. Splenium of corpus callosum: patterns of interhemispheric interaction in children and adults. Neural Plast 2013;2013: 639430 CrossRef Medline

28. Dąmbska M, Wisniewski KE. Normal and Pathologic Development of the Human Brain and Spinal Cord. London: John Libbey; 1999

29. Luders E, Thompson PM, Toga AW. The development of the corpus callosum in the healthy human brain. J Neurosci 2010;30:10985-90 CrossRef Medline

30. Schafer DP, Custer AW, Shrager P, et al. Early events in node of Ranvier formation during myelination and remyelination in the PNS. Neuron Glia Biol 2006;2:69-79 CrossRef Medline 